\title{
Erratum to: Monitoring an ecosystem at risk: What is the degree of grassland fragmentation in the Canadian Prairies?
}

\author{
Laura Roch • Jochen A. G. Jaeger
}

Published online: 28 January 2014

(C) Springer International Publishing Switzerland 2014

\section{Erratum to: Environ Monit Assess \\ DOI 10.1007/s10661-013-3557-9}

The original version of this article unfortunately contained a mistake which stems from the results reported in Table 5 on page 14: There was a miscalculation in the amounts of suitable area in the four fragmentation geometries in the three provinces (the subtraction of the barrier areas was not taken into account). The page numbers relate to the initial online publication dated 04 January 2014. The corrected table is given below.

The online version of the original article can be found at http://dx. doi.org/10.1007/s10661-013-3557-9.

L. Roch · J. A. G. Jaeger $(\bowtie)$

Department of Geography, Planning and Environment, Concordia University Montreal,

1455 De Maisonneuve Blvd. West, Suite H1255, Montreal, QC H3G 1M8, Canada

e-mail: jochen.jaeger@concordia.ca

L. Roch

e-mail: lauraroch5@gmail.com 
Table 5 Total land cover areas related to grassland for the Prairie Ecozone, Alberta, Saskatchewan, and Manitoba. In the four FGs, the areas taken up by $\mathrm{CanVec}$ barriers were subtracted from the total land cover areas to determine the amount of suitable area. In addition, the median, minimum, and maximum values of the remaining patch sizes of potentially suitable areas (i.e., grassland or related) considered in the four FGs are listed

\begin{tabular}{|c|c|c|c|c|}
\hline \multirow[b]{2}{*}{ Land-cover type } & \multicolumn{4}{|c|}{ Total land-cover amount $\left(\mathrm{km}^{2}\right)$ without considering CanVec barriers (Tab. 3) } \\
\hline & Prairie Ecozone & Alberta & Saskatchewan & Manitoba \\
\hline Fallow & $13,847.558$ & $1,172.163$ & $12,216.203$ & 459.193 \\
\hline Grassland & $89,881.299$ & $44,410.608$ & $36,952.295$ & $8,518.396$ \\
\hline Hay/Pasture & $62,678.213$ & $19,568.146$ & $36,492.404$ & $6,617.663$ \\
\hline Shrubland & $13,852.565$ & $4,636.424$ & $7,044.421$ & $2,171.720$ \\
\hline \multirow[t]{2}{*}{ Wetland } & $9,947.429$ & $3,432.846$ & $4,233.499$ & $2,281.084$ \\
\hline & \multicolumn{4}{|c|}{ Total suitable area $\left(\mathrm{km}^{2}\right)$ after the subtraction of the CanVec barrier areas } \\
\hline FGs & Prairie Ecozone & Alberta & Saskatchewan & Manitoba \\
\hline FG1 & $183,241.176$ & $70,110.733$ & $93,678.580$ & $19,451.863$ \\
\hline FG2 & $169,572.694$ & $68,954.229$ & $81,621.909$ & $18,996.556$ \\
\hline FG3 & $108,372.419$ & $49,890.200$ & $45,990.042$ & $12,492.177$ \\
\hline \multirow[t]{3}{*}{ FG4 } & $87,568.592$ & $43,187.443$ & $36,039.198$ & $8,341.951$ \\
\hline & \multicolumn{4}{|c|}{ Amount of suitable area in the Prairie Ecozone $\left(\mathrm{km}^{2}\right)$} \\
\hline & FG1 & FG2 & FG3 & FG4 \\
\hline Sum & $183,241.176$ & $169,572.694$ & $108,372.419$ & $87,568.592$ \\
\hline Median patch size & $6.21 \mathrm{E}-03$ & $6.18 \mathrm{E}-03$ & $6.04 \mathrm{E}-03$ & $6.26 \mathrm{E}-03$ \\
\hline Min patch size & $9.6 \mathrm{E}-12$ & $9.6 \mathrm{E}-12$ & $4.5 \mathrm{E}-12$ & $2.9 \mathrm{E}-12$ \\
\hline Max patch size & $1,114.247$ & $1,111.193$ & 981.641 & 856.933 \\
\hline
\end{tabular}

According to the amended values in Tab. 5, some other values in the abstract and body of the paper also need to be corrected as these numbers are referenced in the text:

In the abstract: The grassland area remaining amounts to $87,568.592 \mathrm{~km}^{2}$ in FG4 (strict grassland definition) and $183,241.176 \mathrm{~km}^{2}$ in FG1 (broad grassland definition), out of $461,503.972 \mathrm{~km}^{2}$ (entire Prairie Ecozone area).

Page 15: When only considering the AAFC's true grassland class, only $87,568.592 \mathrm{~km}^{2}$ of grassland area remain, and FG4 results in a much lower $m_{\text {eff }}$ value of $14.23 \mathrm{~km}^{2}$, a $44.1 \%$ decrease from FG1.

Page 19, first row of Table 7:

\begin{tabular}{|c|c|c|c|c|c|c|c|c|c|}
\hline \multirow{3}{*}{$\begin{array}{l}\text { Name } \\
\text { Prairie Ecozone }\end{array}$} & \multirow{3}{*}{$\begin{array}{l}\text { Area }\left(\mathbf{k m}^{\mathbf{2}}\right) \\
461,503.972\end{array}$} & \multicolumn{4}{|c|}{ Total amount of suitable area $\left(\mathrm{km}^{2}\right)$} & \multicolumn{4}{|c|}{ Effective mesh size: $m_{\text {eff }}\left(\mathrm{km}^{2}\right)$} \\
\hline & & FG1 & FG2 & FG3 & \multirow{2}{*}{$\begin{array}{l}\text { FG4 } \\
87,568.592\end{array}$} & FG1 & \multirow{2}{*}{$\begin{array}{l}\text { FG2 } \\
24.669\end{array}$} & \multirow{2}{*}{$\begin{array}{l}\text { FG3 } \\
18.912\end{array}$} & \multirow{2}{*}{$\begin{array}{l}\text { FG4 } \\
14.233\end{array}$} \\
\hline & & $183,241.176$ & $169,572.694$ & $108,372.419$ & & 25.443 & & & \\
\hline & \multicolumn{4}{|c|}{ Effective mesh density: $s_{\text {eff }}\left(\right.$ meshes per $1,000 \mathrm{~km}^{2}$ ) } & \multicolumn{5}{|c|}{ Fragmentation per se: $m_{\text {eff_per_se }}\left(\mathrm{km}^{2}\right)$} \\
\hline Name & FG1 & FG2 & FG3 & FG4 & FG1 & FG2 & FC & & FG4 \\
\hline Prairie Ecozone & 39.30 & 40.54 & 52.88 & 70.26 & 64.080 & 67.138 & & 537 & 75.011 \\
\hline
\end{tabular}


Page 21: For example, the $m_{\text {eff }}$ value of the Prairie Ecozone of $14.233 \mathrm{~km}^{2}$ in FG4 can be partitioned into the two components:

$\frac{A_{\text {total_suitable }}}{A_{\text {total_landscape }}}=\frac{87,568.592 \mathrm{~km}^{2}}{461,503.972 \mathrm{~km}^{2}}=18.97 \%$

and $m_{\text {eff_per_se }}=\frac{A_{\text {total_landscape }}}{A_{\text {total_sutable }}} \cdot m_{\text {eff }}=\frac{461,503.972 \mathrm{~km}^{2}}{87,568.592 \mathrm{~km}^{2}} \cdot$ $14.233 \mathrm{~km}^{2}=75.01 \mathrm{~km}^{2}$

using the values from Table 7. Similarly, the value of $m_{\text {eff }}=25.443 \mathrm{~km}^{2}$ in FG1 is the product of the two components:

$\frac{A_{\text {total_suitable }}}{A_{\text {total_landscape }}}=\frac{183,241.176 \mathrm{~km}^{2}}{461,503.972 \mathrm{~km}^{2}}=39.71 \%$

and $m_{\text {eff_per_se }}=64.080 \mathrm{~km}^{2}$, indicating that the degree of fragmentation per se of remaining suitable area is actually higher in FG1 than in FG4.

Page 23: The total area of the land-cover type "grassland" in FG4 is $87,568.592 \mathrm{~km}^{2}$ out of a possible area of $461,503.972 \mathrm{~km}^{2}$, i.e. $18.97 \%$ of the study area. The corresponding percentages are $39.71 \%$ for FG1, $36.74 \%$ for FG2, and $23.48 \%$ for FG3 (Table 7), somewhat similar to estimates given in the literature. The study by the Federal, Provincial and Territorial Governments of
Canada (2010) stated that mixed and fescue grassland cover over $110,000 \mathrm{~km}^{2}$. This is well in the range provided by the four FGs from $87,568.592 \mathrm{~km}^{2}$ (FG4) to $183,241.176 \mathrm{~km}^{2}$ (FG1) of our study.

Gauthier \& Wiken (2003) estimated that $25-30 \%$ of the native grasslands remain in the Canadian prairies and parklands. Our value of $87,568.592 \mathrm{~km}^{2}$ seen as the 25 $30 \%$ estimate of remaining grasslands would imply an original total area between $291,895.306 \mathrm{~km}^{2}$ and $350,274.368 \mathrm{~km}^{2}$ for FG4 and between $610,803.920$ $\mathrm{km}^{2}$ and $732,964.704 \mathrm{~km}^{2}$ for FG1, meaning that $63.24 \%-100 \%$ of the Prairie Ecozone was once covered by grasslands.

In addition to these value changes, on page 5 the name of a species was misspelt ("Sprague's Pipet"), which should read Sprague's Pipit.

Page 25: We would also like to use this opportunity to clarify the role of the Conservation Areas Reporting And Tracking System (CARTS). The CARTS itself does not protect any areas, but is merely a compilation of protected areas as recognized by appropriate jurisdictions and therefore, strictly speaking, there are no "CARTS regions". It is more appropriate to refer to these "CARTS regions" simply as protected areas (which have been classified by various IUCN protected areas categories) that have been complied in this CARTS database.

We apologize for any inconvenience that our mistakes in the original version may have caused. 